\title{
INFLUENCIA DA ANTRAQUINONA NO TEMPO E TEMPERATURA DE COZIMENTO DE Eucalyptus grandis
}

\author{
M. K. da SILVA ${ }^{1}$, N. R. C. FERNANDES-MACHADO ${ }^{2}$ \\ Universidade Estadual de Maringá, Departamento de Engenharia Química \\ E-mail para contato: $\underline{\text { mkalinke } @ \text { yahoo.com.br }}$
}

\begin{abstract}
RESUMO - O Brasil é um dos grandes produtores de celulose, pois o clima e a extensão territorial permitem obter grandes áreas de reflorestamento em poucos anos, obtendo-se polpas de celulose altamente competitivas no mercado mundial. Para aumentar sua produção, os produtores de celulose buscam alternativas para acelerar a remoção de lignina durante o cozimento. As condições altamente alcalinas do processo reacional heterogêneo em alta temperatura dificultam a aplicação de catalisadores que muitas vezes são instáveis nessas condições de processo. A antraquinona (AQ) destaca-se por acelerar a deslignificação e ao mesmo tempo estabilizar os carboidratos. Neste sentido, o presente trabalho avaliou a deslignificação ao longo do cozimento de Eucalyptus grandis na ausência e presença de AQ. Os resultados mostraram a eficiência da AQ no aumento de rendimento do processo e na deslignificação somente após atingir a temperatura máxima de cozimento. Em temperatura mais baixa a AQ revelou-se mais eficaz.
\end{abstract}

\section{INTRODUÇÃO}

O desenvolvimento de produtos que são facilmente recicláveis, de fonte renovável e que proporcione menores problemas ambientais, tem ampliado as aplicações de papel e consequentemente o seu consumo. Como exemplo podemos citar o setor das embalagens, que tem substituído parte das embalagens plásticas por papéis com alta tecnologia que preservam a qualidade do produto embalado, gerando resíduos menos agressivo ao meio ambiente. Como consequência do crescente consumo de papel, a demanda por polpa celulósica que atendam a qualidade exigida pelas fábricas de papel tem aumentado.

O Brasil é um dos grandes produtores de celulose fibra curta, pois o clima e a extensão territorial permitem obter grandes áreas de reflorestamento em poucos anos, gerando polpas de celulose altamente competitivas no mercado mundial.

Atualmente a polpação Kraft (sulfato) é a tecnologia de polpação química dominante mundialmente, utilizando como agentes ativos do cozimento o hidróxido de sódio $(\mathrm{NaOH})$ e sulfeto de sódio $\left(\mathrm{Na}_{2} \mathrm{~S}\right)$ (Bajpai, 2011). Como desvantagens a polpação química possui um baixo rendimento do processo, variando entre 45 e 55\%, e uma polpa marrom devido a um residual de lignina ao final do processo, necessitando de mais uma etapa para produção de polpa branca. 


\section{9 a 22 de outubro de 2014 \\ Florianópolis/SC}

A madeira é a principal fonte de fibras para obtenção de polpa celulósica. As fibras presentem na madeira estão unidas pela lamela média que tem em sua composição grande quantidade de lignina. A individualização das fibras é realizada em um reator pressurizado denominado digestor, onde os cavacos reagem com o licor branco, solução de hidróxido de sódio $(\mathrm{NaOH})$ e sulfeto de sódio $\left(\mathrm{Na}_{2} \mathrm{~S}\right)$, para remoção da lignina.

Durante a polpação Kraft parte da celulose e a hemicelulose são degradadas juntamente com a lignina, principalmente por causa das reações de hidrólise alcalina e despolimerização terminal que ocorrem a altas temperaturas.

Desta forma, muitas pesquisas vêm sendo desenvolvidas na tentativa de minimizar as perdas dos polissacarídeos e acelerar a velocidade da reação de deslignificação. Uma alternativa que atende a essa exigência é a aplicação de catalisadores. Entretanto, as condições altamente alcalinas do processo reacional heterogêneo que ocorre em alta temperatura dificultam a aplicação de catalisadores, que muitas vezes são instáveis nessas condições de processo.

Os compostos quinônicos têm demostrado serem eficientes no processo de polpação por acelerar a deslignificação e ao mesmo tempo estabilizar as reações de despolimerização terminal dos carboidratos. Dentre esses compostos, a antraquinona tem se destacado e atualmente é o catalisador mais utilizado nas indústrias de celulose.

Inúmeras variáveis influenciam no rendimento da polpação Kraft. Macleod (2007) relacionou os principais fatores que afetam o rendimento da polpa. Dentre os fatores mencionados os químicos convencionais utilizados afetam diretamente o rendimento, pois o processo de deslignificação não é seletivo, afetando os polissacarídeos. Para amenizar este problema inúmeras modificações foram realizadas na polpação Kraft na década de 1980, baseada em princípios químicos que tornassem o processo mais seletivo para a deslignificação sobre a degradação da holocelulose (celulose + hemicelulose). Uma das alternativas foi a utilização de aditivos como antraquinona, que aumenta o rendimento da polpa entre 1-3\% podendo ser utilizado em todos os tipos de digestores sem nenhuma modificação no equipamento.

A antraquinona é um catalisador redox estável a alta temperatura e soluções fortemente alcalina que catalisa a degradação da lignina e, simultaneamente, estabiliza os carboidratos, atuando em um ciclo redox permitindo trabalhar em baixa quantidade (Li et al. (1998), Santiago e Neto, 2008).

Em função da capacidade de atuação da antraquinona tanto nos carboidratos quanto na lignina, faz dela um importante caminho para otimizar inúmeras variáveis no processo, como tempo e temperatura de cozimento, carga de álcali ativo, teor de sulfidez sem que o rendimento do processo seja prejudicado.

Jerônimo et al. (2000) avaliaram a adição da AQ em diferentes maneiras na polpação alcalina de Eucalyptus saligna. Eles compararam cozimento convencional $\left(170^{\circ} \mathrm{C}\right)$ e cozimentos longos $\left(30\right.$ min a $130^{\circ} \mathrm{C}, 165$ min a $155^{\circ} \mathrm{C}$ ) para um mesmo fator $\mathrm{H}$. Os cozimentos longos apresentaram maior rendimento devido a condições mais amenas durante o cozimento (menor temperatura). A 


\section{9 a 22 de outubro de 2014 \\ Florianópolis/SC}

média no aumento de rendimento para as diferentes sulfidez utilizadas foi de $1,4 \%$. Isso para uma fábrica de 1000 toneladas/dia de polpa representa uma economia de $103 \mathrm{~m}^{3} / \mathrm{dia}$ de madeira com densidade básica de $0,5 \mathrm{~g} / \mathrm{cm}^{3}$.

Santiago e Neto (2008) analisaram o processo de deslignificação de Eucalyptus globulus na ausência e presença da antraquinona durante todo o processo de polpação: impregnação, aquecimento e cozimento. Eles verificaram que a antraquinona não proporcionou melhoria na velocidade de deslignificação durante a fase de impregnação e aquecimento. Sua presença melhorou a velocidade de deslignificação reduzindo o tempo de cozimento e consequentemente levou a uma economia de álcali de $8 \%$. O efeito catalítico da $\mathrm{AQ}$ só foi notado quando a temperatura atingiu o máximo $\left(160^{\circ} \mathrm{C}\right)$, acelerando a velocidade de deslignificação, reduzindo o tempo de permanência na temperatura máxima de cozimento em $50 \%$.

Neste sentido, o presente trabalho tem como objetivo realizar um estudo da deslignificação da polpação Kraft de Eucalyptus grandis e contribuir para o aumento do rendimento da polpação aplicando antraquinona a $165^{\circ} \mathrm{C}$ e $170^{\circ} \mathrm{C}$.

\section{MATERIAIS E MÉTODOS}

Para a realização dos testes de deslignificação, o licor de cozimento Kraft $\left(\mathrm{NaOH}\right.$ e $\left.\mathrm{Na}_{2} \mathrm{~S}\right)$ foi preparado em laboratório com $20 \%$ de sulfidez. Os cavacos utilizados foram de Eucalyptus grandis com sete anos de idade, os quais foram classificados manualmente para eliminar grandes variações no tamanho de cavaco.

Os cozimentos experimentais foram realizados em unidade reacional de aço inoxidável de $250 \mathrm{~mL}$, acopladas a um sistema rotativo no interior de uma estufa para controle da temperatura e uniformização da solução no interior da câmera. Nos testes de deslignificação, as corridas iniciaram com uma etapa de impregnação de 40 minutos na temperatura de $120^{\circ} \mathrm{C}$, e em seguida uma rampa de aquecimento de 20 minutos até a temperatura máxima de cozimento. As amostras foram coletadas após $40 \mathrm{~min}$ (final impregnação), $60 \mathrm{~min}$ (final aquecimento), e oito amostras na temperatura máxima de cozimento. O tempo total de cozimento variou em função da temperatura de cozimento. As condições estabelecidas para os cozimentos foram: 18\% Álcali Ativo, 20\% Sulfidez e relação licor/madeira 4:1.

O acompanhamento da deslignificação foi realizado através da lignina degradada e solubilizada no licor negro residual (LN). A alíquota de $\mathrm{LN}$ foi diluída em $\mathrm{NaOH} 0,01 \mathrm{~N}$ e analisada em espectrofotômetro UV. A absorbância para lignina foi medida em $213 \mathrm{~nm}$. O comprimento de onda e a curva de calibração foram obtidos utilizando lignina comercial da Aldrich.

As quatro amostras finais do cavaco cozido foram desagregadas, depuradas (para eliminar o rejeito) e lavadas para determinação do rendimento bruto (aceite + rejeito), rendimento depurado (aceite) e teor de rejeitos.

A comparação entre as curvas de deslignificação foram analisadas em função do tempo e fator 
H, variável que correlaciona o tempo e temperatura de cozimento através da Equação 1.

$$
\text { fator } H=\int_{0}^{t} \exp \left(43,2-\frac{16113}{T}\right) d t
$$

\section{RESULTADOS E DISCUSSÕES}

A adição da antraquinona na polpação Kraft de Eucalyptus grandis proporcionou um aumento na velocidade de deslignificação nas temperaturas de cozimento analisadas conforme mostra a Figura 1 .

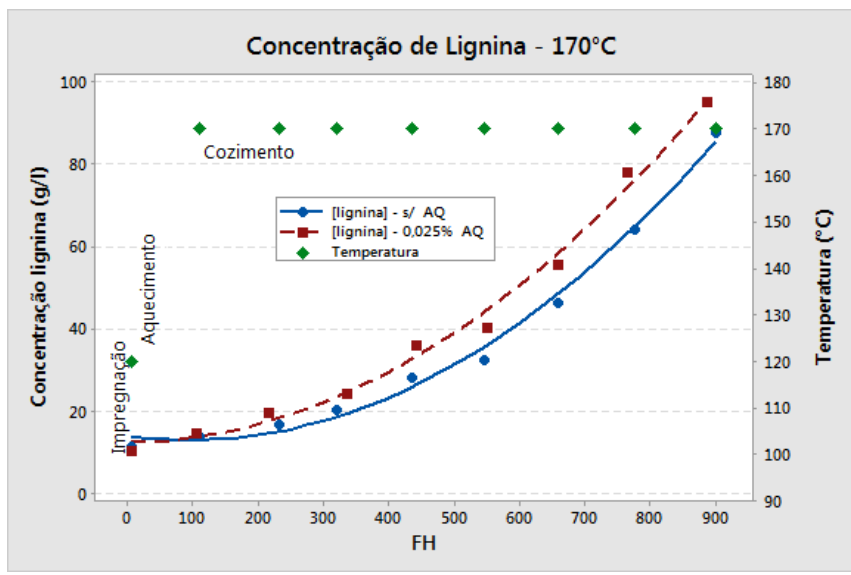

(a)

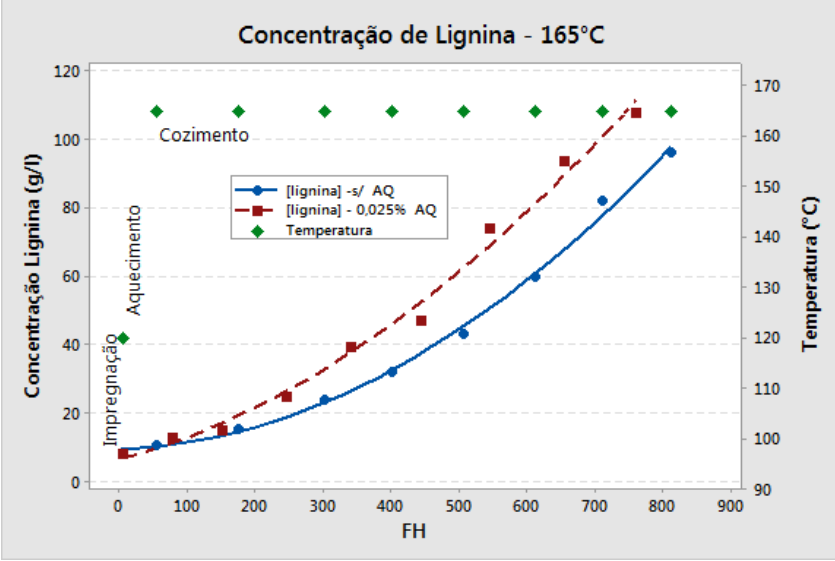

(b)

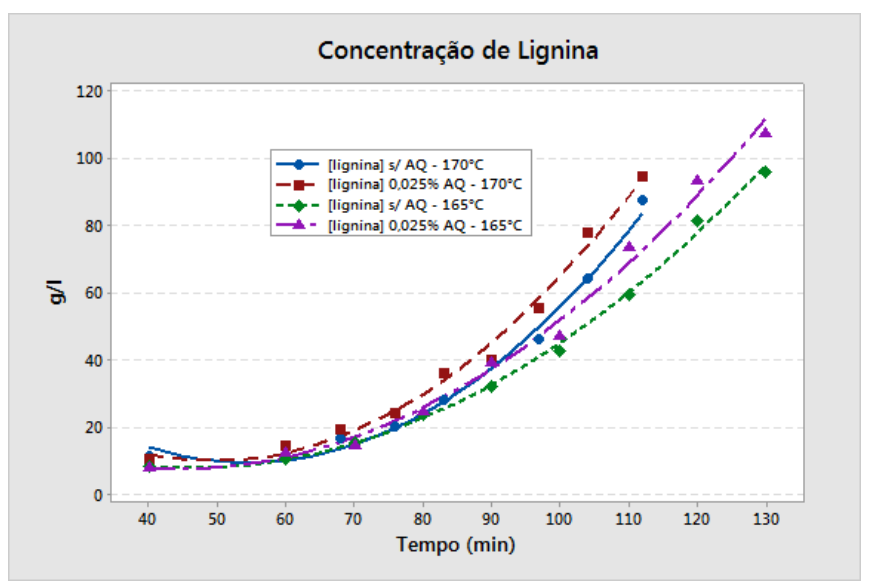

(c)

Figura 1 - Concentração de lignina ao longo do cozimento Kraft de Eucalyptus grandis. (a) $170^{\circ} \mathrm{C}$ em função $\mathrm{FH}$ (b) $165^{\circ} \mathrm{C}$ em função $\mathrm{FH}$ (c) comparação 170 e $165^{\circ} \mathrm{C}$ em função do tempo

$\mathrm{Na}$ fase de impregnação e aquecimento até a temperatura máxima a antraquinona não 
apresentou efeito catalítico na deslignificação. A eficiência da antraquinona só foi observada após atingir a temperatura máxima de cozimento. O comportamento obtido para Eucalyptus grandis foi semelhante ao encontrado por Santiago e Neto (2008) para Eucalyptus globulus. Este comportamento acontece porque a ação da antraquinona na polpação Kraft ocorre por transferência de elétrons dos carboidratos para a lignina (ciclo redox) como mostra a Figura 2. Para que a antraquinona tenha efeito catalítico sobre o cozimento é necessário oxidar os grupos terminais redutores dos carboidratos a um ácido aldônico formando a hidroquinona (AHQ) que promove a redução da lignina, levando a fragmentação e solubilização da mesma. Entretanto a AQ é insolúvel no licor de cozimento, dificultando sua impregnação nos cavacos. Yang et al. (2003) analisaram a solubilidade da antraquinona na solução alcalina e observaram que a solubilidade da AQ é muito baixa $(0,02 \mathrm{~g} / \mathrm{L}$ a $90^{\circ} \mathrm{C}$ ) e lenta.

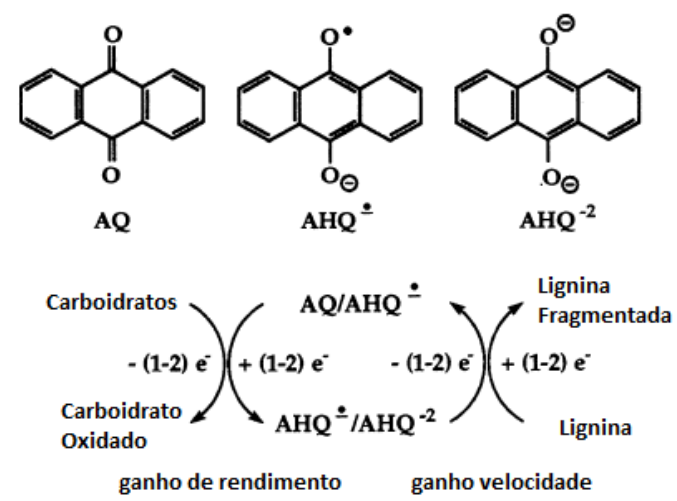

Figura 2 - Ciclo redox da AQ com os componentes da madeira (DIMMEL, 1996)

$\mathrm{O}$ aumento na velocidade de deslignificação com AQ promoveu um aumento do rendimento depurado como mostra a Figura 3 para as temperaturas de cozimento analisadas.

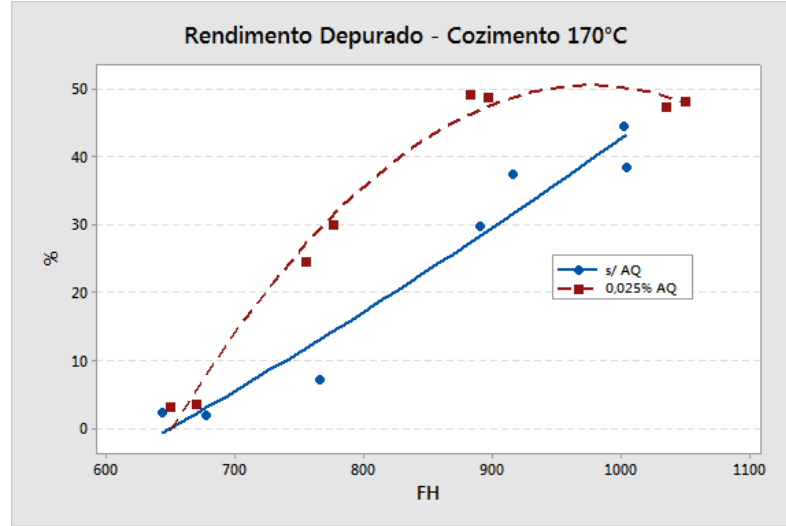

(a)

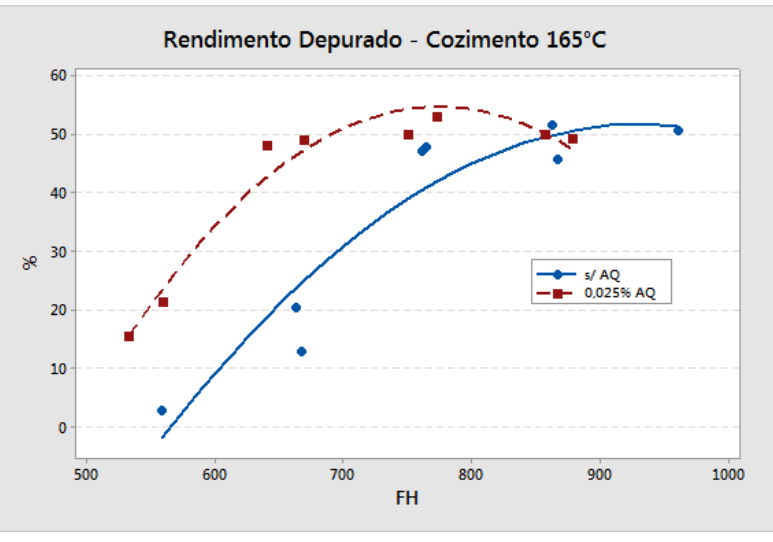

(b)

Figura 3 - (a) Rendimento depurado $170^{\circ} \mathrm{C}$ (b) Rendimento depurado $165^{\circ} \mathrm{C}$

$\mathrm{O}$ rendimento depurado atinge valores máximos com fator $\mathrm{H}$ menor, ou seja, menor tempo de 
cozimento quando $0,025 \%$ de AQ são adicionados ao licor de cozimento. Dois fatores contribuem para este aumento, a ação da antraquinona sobre os carboidratos, estabilizando os grupos terminais redutores, e o menor tempo de exposição dos carboidratos ao licor de cozimento.

A eficiência da antraquinona na deslignificação também pode ser observada pelo teor de rejeitos como mostra a Figura 4. A adição da antraquinona promove a total individualização das fibras com fator $\mathrm{H}$ mais baixo comparado a polpa sem AQ, resultante da ação da antraquinona sobre a lignina contida na lamela média.

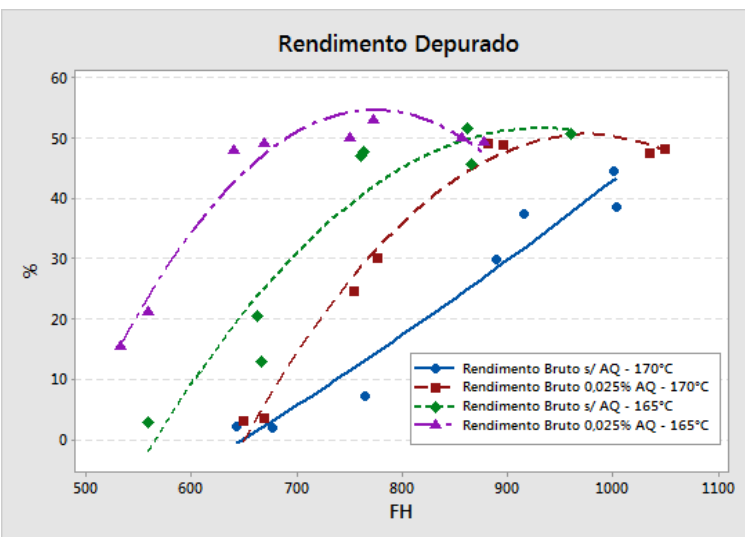

(a)

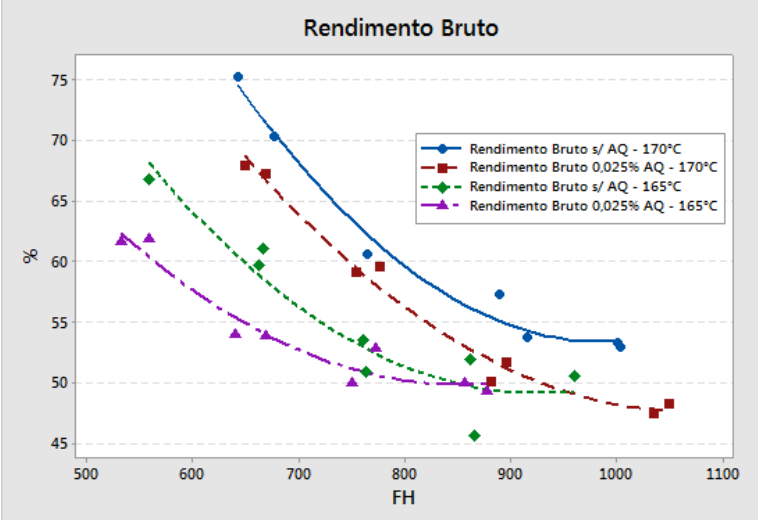

(b)

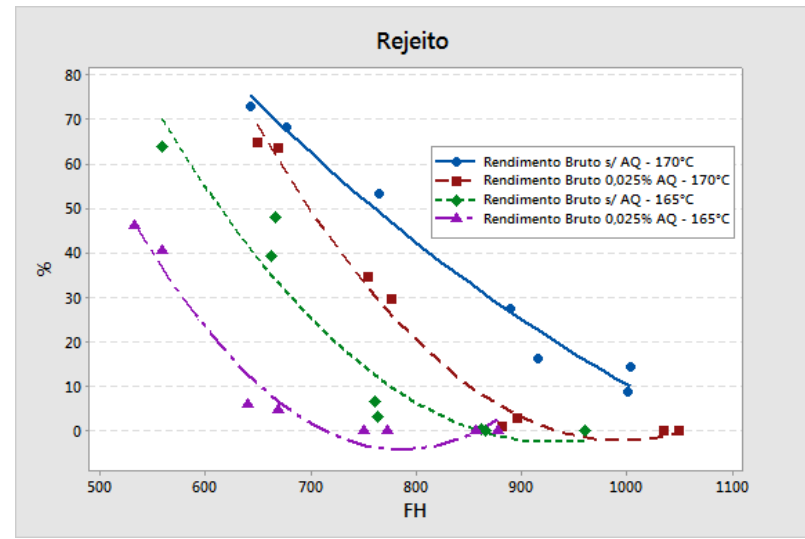

(c)

Figura 4 - (a) Rendimento depurado em função do tempo a $170^{\circ} \mathrm{C}$ e $165^{\circ} \mathrm{C}$; (b) Rendimento Bruto à $170^{\circ} \mathrm{C}$ e $165^{\circ} \mathrm{C}$ (c) Rejeito à $170^{\circ} \mathrm{C}$ e $165^{\circ} \mathrm{C}$

Comparando o rendimento depurado na temperatura de $170^{\circ} \mathrm{C}$ e $165^{\circ} \mathrm{C}$ observamos que a temperatura mais baixa resultou em rendimento depurado mais elevado.

Ao comparar os cozimentos nas temperaturas analisadas observamos que a $0,025 \%$ de AQ 
permite reduzir a temperatura de $170^{\circ} \mathrm{C}$ para $165^{\circ} \mathrm{C}$ sem grandes variações na velocidade de deslignificação como mostra a Figura 5. A redução na temperatura no mesmo tempo de cozimento resulta em polpas com maior rendimento devido a condições mais amenas durante o cozimento.
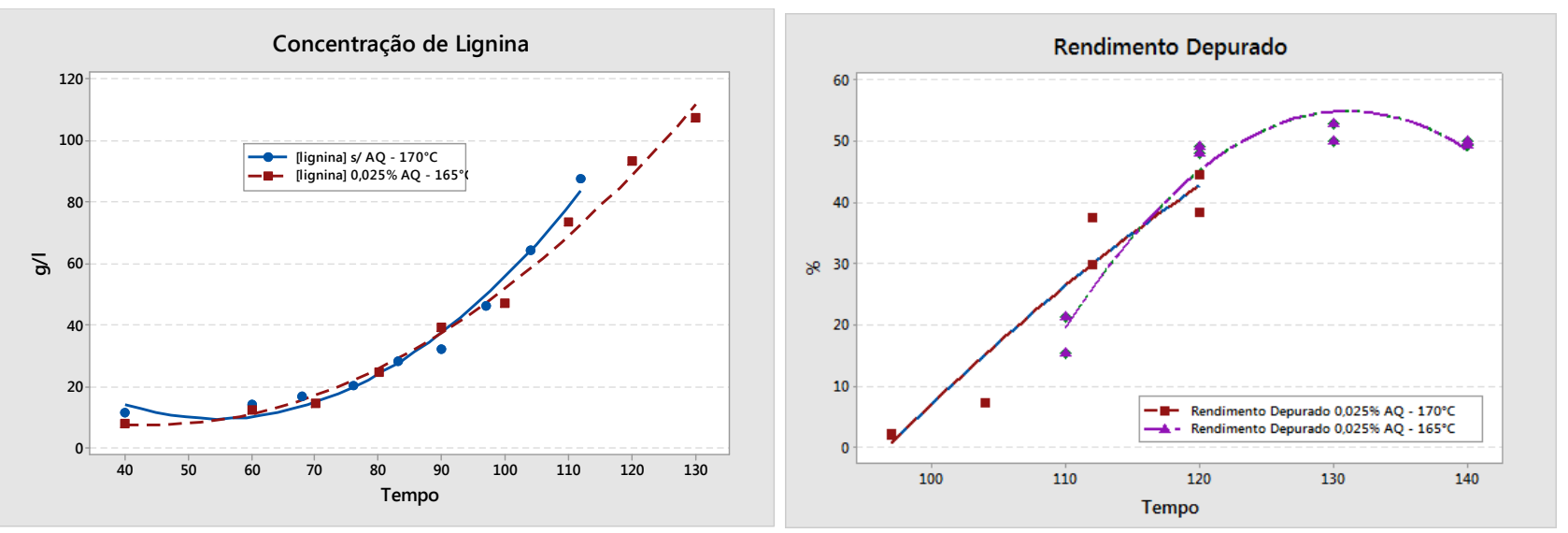

Figura 5 - Comparação entre polpação $170^{\circ} \mathrm{C}$ sem $\mathrm{AQ}$ e $165^{\circ} \mathrm{C}$ com $0,025 \% \mathrm{AQ}$

\section{CONCLUSÃO}

A adição de $0,025 \%$ de antraquinona na polpação Kraft de Eucalyptus grandis permitiu a redução na temperatura de cozimento de $170^{\circ} \mathrm{C}$ para $165^{\circ} \mathrm{C}$, sem alterações no tempo de cozimento. As condições mais amenas de temperatura resultaram e um aumento no rendimento depurado impactando nos maiores custos na indústria de celulose. A temperatura mais baixa reduz o consumo de energia, e o maior rendimento depurado resulta na economia de madeira, com baixas quantidades de antraquinona, mostrando ser um catalisador eficiente para polpação Kraft de Eucalyptus grandis.

\section{REFERENCIAS}

BAJPAI, P. Biotechnology for Pulp and Paper Processing. XXI, 414 p. Cap. 2 p.. 7-14, 2012.

DIMMEL, D. R. Pulping with Anthraquinone: Fundamental Chemstry. TAPPI Pulping Conference Procedings, p 53-58, 1996.

JERÔNIMO, L. H.; FOELKEL; C. E. B.; FRIZZO, S. M. B. Utilização de antraquinona na produção de polpa sulfato de Eucalyptus saligna e seus efeitos no branqueamento", In: Ciadicyp - congr. iberoamericano de investigación en celulosa y papel, 2000, Iguazú/ Prov. de Missiones/ Ar, 2000.

LI, Z.; MA, H., KUBES; G. J., LI, J. Synergistic Effect of Kraft Pulping with Polysulphide and Anthraquinone on Pulp-yield improvement. Journal of pulp and paper science, vol 24 n. 8 p. 237241, 1998.

MACLEOD, M. The top ten factors in kraft pulp yield. Paperi ja Puu-Paper and Timber Vol. 89, n. 4, 2007. 
SANTIAGO, A. S.; NETO, C. P.. Impact of Kraft Process Modifications on Eucalyptus globulus Pulping Performance and Polysaccharide Retention. Ind. Eng. Chem. Res. 47, p. 7433-7440, 2008.

YANG, X. T.; CHAI, X. S.; HOU, Q. X.; ZHU, J. Y.; DANIELSSON, L. G. Spectroscopic Determination of anthraquinone in kraft pulping liquors using a nafion membrane interface. Journal of pulp and paper science, vol. 29 n. 9, p. 299-302, 2003. 